\begin{tabular}{|ccc|}
\hline & ANNALES INSTITUTI SLAVICI \\
& UnIVERSITATIS DEBRECENIENSIS & \\
SLAVICA XLIX & 2020 & DEBRECEN \\
\hline
\end{tabular}

Ангелика МОЛНАР

\title{
МЕТАФОРИЗАЦИЯ В РАССКАЗЕ «ПИКОВАЯ ДАМА» ЛюДМИЛЫ УЛИЦКОЙ*
}

\author{
Metaphors in Lyudmila Ulitskaya's \\ Short Story "The Queen of Spades"
}

\begin{abstract}
This paper opens up how Lyudmila Ulitskaya in her short story "The Queen of Spades" develops the crisis situation which her heroes gets into. So, the problems of the crisis should be analysed also from a broader perspective, however, we will confine ourselves to only one rather narrow aspect of the analysis of poetic utterance, namely the tropological one. The chosen (mechanical and animalistic) metaphors are connected with the figure of the main heroine and also her revolting daughter.
\end{abstract}

Keywords: Ulitskaya, The Queen of Spades, figures, heroes, metaphors

\section{Введение}

Целью статьи является изучение того, как в рассказе Л.Е. Улицкой «Пиковая Дама» метафоры трансфигурируются на уровне сюжета в тематические единицы, конкретизируя новую семантику и призывая к новой интерпретации.

Научная литература. В центре внимания разных (в том числе, гендерных, женских, психоаналитических и т.п.) интерпретаций стоят разные вопросы современного переосмысления классической повести А.С. Пушкина «Пиковая дама» [ПоБИВАЙЛО 2007; САВКИНА 2016; ШтыРОВА 2013]. Выявляется, как в рассказе Улицкой используются литературные традиции [ЗАВьялОВА 2016] и поэтические формы [ИШКИНА 2003; КОЛядич 2004; САФОНОВА 2009]. Лингвосемантическая классификация некоторых метафорических образов также представлена [МолНАР - НиколинА 2019], однако требуется ее восполнение литературной интерпретацией.

Методология. Художественный язык современной русской прозы определяют не только стилистические и другие особенности, или же полное отсутствие традиционных поэтических средств. Следует обратить внимание и на формы порождения тропов, которые создают новое значение, и на языковые трансфигурации, которые образуют новые знакосочетания. План словесного оформления, «высказывание» же и в современной литературе может демонстрировать как знакообразование, так и реализацию поэтических средств, т.е.

Работа выполнена при поддержке гранта РФФИ 19-512-23004 «Метафорическая картина мира современной русской и венгерской прозы конца XX - начала XXI в. (сопоставительный анализ)». 
создание языковых и семантических метафор, ибо именно они превращают прозаические произведения в поэтические. Более того, метафоризация и в современной литературе тесно взаимосвязана как с пониманием, так и с экзистенциальными вопросами.

\section{Основная часть}

Если же воспринимать метафору как обязательное условие человеческого понимания, и перефразировав это же определение при помощи метафоры, то первая фраза Людмилы Улицкой в рассказе «Пиковая дама» представляется «метафорой метафор»:«то ли колесики в мировом часовом механизме поистерлись, то ли зубчики съелись - только время стало катиться ускоренно, то и дело впадая в мерцательную аритмию, и так получилось, что по ходу движения этого ущербного времени...» [УЛИЦКАЯ 2006: 87]. В данном случае не достаточно причислять ее к бытовым, тривиальным тропам («время как машина»), так как она - новая метафора, не имеющаяся в повести Пушкина, и образует личный, экзистенциальный смысл, относящийся к жизни человека, в данном случае, одной из героинь рассказа Улицкой - Анны Федоровны, дочери Мур, которая старается понять как свою мать, так и себя. Более того, новая семантика тематизируется в поэтическом произведении и приводится как метафора воплощения смерти (в образе Мур).

Это также, как и все остальные определения, присваивается точке зрения Анны Федоровны, следовательно, восприятие героини становится неким «образом слова»: «Она знала все круги, восьмерки и петли, наподобие тех, что в Гришиной железной дороге, по которым скользят паровозики старых мыслей, делая остановки и перекидки в заранее известных местах ее великой биографии〉 [УлИЦКАЯ 2006: 100]. Воспоминания Мур метафоризуются поездом, а образ ее мышления - железной дорогой. Это, с одной стороны, относится к механизму, а с другой, - становится новаторским сближением двух совершенно разных понятий, соотношение которых алогично. Неожиданное сочетание и секвенция звуковых повторов в фразе «мерцательная аритмия» также входит в этот ряд. Языковая метафора, образующаяся из анаграмматических соположений, предвещает и семантический сдвиг в эпитете и управляемом им слове, ибо «мерцание» и «аритмия» никогда не сближаются в бытовой речи, только в рассказе Улицкой. Здесь метафора, относящаяся к неровности времени, распространяется на образ героини «Мур» и ее связь с миром: она охватывает собой все.

Не только особенность мышления, но и дух героини внесен в метафорическое поле текста, относящееся к воспоминанию. Разные значения слова выражаются одной его формой, которая связывает эти значения в тексте рассказа Улицкой. Интересно, что в результате такой операции совпадение знако-звукового состава слов также служит семантическому сближению, присвоенному точке зрения дочери. Здесь явно наблюдается не только языковая игра: «Живая одним духом. Но каков был этот дух, Анна Федоровна знала преотлично. Зажимая в руке новенькую книжку, дух произнес: - Какая глупость понаписана 
в этих воспоминаниях!» [УЛИЦКАЯ 2006: 92]. «Теперь она включалась на духах.» [УЛИЦКАЯ 2006: 100]. Так взаимосвязываются мысли, тело и дух Мур.

В тексте рассказа данное соотношение распространяется и на другие слова с целью конкретизации абстрактного: «Кому-то могло показаться, что мысли у старушки скачут, как голодные блохи, но Анна Федоровна знала об удивительной материнской особенности: она всегда думала о нескольких вещах одновременно, как будто плела пряжу из нескольких нитей» [УлицКАЯ 2006: 105]. Итак, мышление сравнивается с блохами по признаку прыжка, но обогащается и через посредство эффектного эпитета «голодные». Кроме того, и пряжение нитей присваивается образу, тем самым распространяя поэтизацию на еще одну вещь, далекую по значению от имеющихся. Отметим, что в силу такого сближения отдаленных образов, фигура Парки также включается в ассоциативный ряд, выстраиваемый в тексте в связи с Мур: она наделяется способностью плести и отрывать жизнь человека [МолНАР - НиколинА 2019: 97]. Героиня в самом деле больше чем причастна как рождению и жизни, так и смерти Анны Федоровны.

В тексте рассказа не только имя, но и прозвище «Пиковая Дама» становится темой, реализуясь с новой семантикой. Главную героиню Мур отождествляет с пушкинской героиней Марек, бывший муж ее дочери Анны Федоровны: «А матушка твоя - настоящая Пиковая дама. Пушкин с нее писал» [УлИЦКАЯ 2006: 118]. Это он, как генератор главного конфликта сюжета (попытки освободить семью от рабства / опекания Мур), вводит литературную интерпретационную линию в рассказ. Ее фигура и в самом деле является воплощением заглавия рассказа.

Описание внешних черт старухи Улицкой реализует «мертвенность» ее образа. Следующее сравнение служит выражению сходства с образом Вия, кроме того, включается и функция зеркальности: Мур «медленно двигала длинными веками и неодобрительно смотрела на Анну Федоровну глазами цвета пустого зеркала» [УлиЦКАЯ 2006: 91]. Пустота, которая определяет образ героини, появляется и в развернутом сравнении, ставшем метафорой жизни Мур. Героиня ходит в черном, что и соответствует карточной масти: «Черное кимоно висело пустыми складками, как будто никакого тела под ним не было. Только желтоватые костяные кисти в неснимающихся перстнях да длинная шея с маленькой головой торчали, как у марионетки» [УЛИЦКАЯ 2006: 91]. Черное кимоно, кажущееся пустым, костлявость рук фигуры, торчащая шея маркируют ее куклообразность (марионетка), т.е. она не простое уподобление, а словно настоящее олицетворение смерти. Возникает аналогия и с другим фольклорным образом - Кощеем Бессмертным [МолНАР - НикОЛИНА 2019: 97].

В этой связи следует обратить внимание и на театральность в презентации героини, связанную с ее желаниями: «в центре пустой сцены оставалась она одна и ее разнообразные желания» [УЛицКАЯ 2006: 105]. Агрессия Мур и подкрепляет ее безграничную власть над родными, их полную подчиненность перед ее бесконечными требованиями. Предметным выражением капризов и повелений «Пиковой дамы» Улицкой становится колокольчик, сопоставляемый 
с цветком:«Бронзовый колокольчик, уткнувшись лепестковым лицом в линялое сукно, стоял перед ней» [УЛИЦКАЯ 2006: 97]. Главный атрибут ее фигуры, вещь воплощает металлическую волю и вегетативную витальность героини. Это выражается на уровне дискурса, в частности, и в фоническом порядке слов с секвенцией *ле/ло. Привычка требовать героиней немедленного удовлетворения всех ее желаний метафоризуется в тексте также при помощи образов войны и угасания огня: «Мур, пришедшая было в боевое настроение, при виде такой находчивости сразу же угасла» [УлицКАЯ 2006: 96].

Более пошлые желания современной Пиковой дамы олицетворяются в тексте, образуя новые метафоры, так как глаголы в данном соотношении раньше не были введены в обиход: «романы наскучили, опреснели, желания потеряли прежнюю упругость» [УлицКАЯ 2006: 133-134], т.е. они старели параллельно телу героини. Подобным образом создаются инновативные сближения и в следующих сочетаниях, которые демонстрируют ненасытную фигуру телесными удовольствиями: был «роман. Ослепительный, невиданный, с молодым актером»; а затем «посыпались одна за другой подруги» [УлицКАЯ 2006: 134]. Неслучайно, вместо глагола «посыпались», означающего в прямом смысле «уронить чего-то сыпучего», приводится слово со значением «подали в ящик».

Пассии позволяют героине одержать верх как над своими соперницамировесницами, так и над смертью. Такой же вещью оказывается молодильный «крем» для кожи, требуемый Мур. Здесь опять употребляется не «стершая метафора», или, по-другому, действенная в повседневной разговорной речи, а новое сравнение: «Так не забудь купить мне крем, - и провела слабыми пальцами по расплывающейся, как старый абрикос, коже» [УлицКАЯ 2006: 105]. В перечислении поклонников Мур также приводится инновативная метафора, созданная в тексте при помощи неожиданных в данном контексте эпитетов. Они обозначают людей с неясным определением пола: «неопределенными существами, находящимися в узком и мучительном зазоре между полами» [УлицКАЯ 2006: 94].

Имя Мур явно содержит и отклик на «кошачий» характер и поведение героини. Русское же слово-сегмент «мур» обозначает главное свойство кошек: мурлыкание. Ласковым назвать героиню рассказа в отношении своих родных нельзя, однако для определения ее связей с мужчинами вполне уместно употребляется указание именно на этот глагол (имя как «индекс»). Итак, с одной стороны, при создании нового слова-имени «Мур» образуется новая метафора (кошка), которая выполняет дополнительную поэтическую функцию в литературном тексте. С другой стороны, внешняя характеристика фигуры Мур однако отражает нечто противоположное органичности, натуральной изящности и пушистой тонкости кошек. Неоднократно подчеркивается ее чопорность и приращенность к ходильной машине - металлическому двигательному механизму, что придает некую машинообразность ее фигуре: «на кухню, поскрипывая колесиками своей ходильной машины, с прямой, как линейка, спиной, явилась Мур» [УлицКАЯ 2006: 90]. Исходная фраза о мироустройстве 
(механизм из колесиков) будто бы повторяется при чтении того, как из инвалидной коляски руководит миром своей семьи Мур.

Кошачьи свойства Мур наблюдаются в ее былых любовных отношениях с мужчинами, которые напоминают поведение «мартовских котов», по крайней мере в восприятии ее дочери, и представляются через посредство выразительных эпитетов, метафор, слов, употребляемых в связи с животными, как например, «течка»: Анна Федоровна будучи подростком «решила, что никогда не выйдет замуж: не было для нее ничего противнее, чем мурлыкающий голос, возбужденный смех и протяжные стоны из материнской спальни... вечный гон, течка, течка...» [УЛИЦКАЯ 2006: 143].

В связи с образом Анны Федоровны раскрываются совершенно иные свойства, чем у Мур: она вносит свет, порядок в мир, устраняет нарушения этого порядка, как на микроуровне глаза, так и макроуровне семьи и мира. Героиня же успешно оперирует людей, исцеляет их, возвращая им зрение, т.е. свет. По этой причине ее рука, которая вооружена инструментом-машиной, особо бережется ею, тем более, что дома она либо прикасается горячего, либо отбивает стекло. Таким образом механика упоминается не только в связи с фигурой Мур. По этой причине и оказывается катастрофическим расстройство Анны Федоровны, сказывающемся на состоянии ее руки. Это также - как необычное сочетание - peпрезентуется и при помощи сравнения после звонка Марека: на героиню нахлфнула «дикая слабость». «Даже от руки кровь отхлынула, ослабли и промялись подушечки пальцев, как после большой стирки» [УлицКАЯ 2006: 102].

Детализация в рассказе раскрывает признаки руки Анны Федоровны («грубая, но умелая), отличающиеся от руки Мур (тонкая, но мертвенная кисть»), и дополняется указанием на горло: «Руки она берегла, как певица горло. ... Каждый день запускала она вооруженные манипулятором руки в самое сердце глаза» [УлиЦКАЯ 2006: 96-97]. Центр глаза, как орган восприятия света, по стершей метафоре именуется сердцем, как органом жизни и человечности. Ряд, состоящий из сплошных глаголов и создающий упорядоченность несовместимых элементов (грубая рука - тонкое чудо), превращается в коренную метафору рассказа, сближающую глаза и механизм: «этими грубоватыми пальцами латала, штопала, подклеивала тончайшее из мировых чудес...» [УлицКАЯ 2006: 97]. Работа героини метафоризуется как «работа ювелира» по общему признаку тонкости и прециозности. Однако можно применить фразу, обозначающую результат последней операции Анны Федоровны: «вся ювелирная работа пошла насмарку» [УЛИЦКАЯ 2006: 130], как в ее работе, так и в семье.

Улицкая оперирует эффектом неожиданных сочетаний и в том случае, когда Анне Федоровне представляется реакция Мур на попытку семьи сбежать от нее. Несовместивые понятия соединяются так, что при вертикальном чтении текста можно обнаружить связь и со «стеклянными глазами» Мур. Итак, с одной стороны, витальная Мур названа «кошкой», «тигрицей на охоте», а с другой, - определения ее фигуры («бледные глаза») и ее слова («стеклянный крик») относятся к смерти. В результате сравнения голоса Мур с осколками разбитой посуды смысл обрастает словно вещным выражением ее истерик. 
Сюда примыкает и предмет (и форма) речи героини: «женский мат». Этим и развивается изначальное сочетание в порождение смысловой равноплановости «нехорошего» слова и «осколочности». Реализуется также созвучие слов «мать» и «мат»: «побледневшие глаза Мур, тихий хрипловатый голос, повышающийся до звонкого стеклянного крика. Осколки разбитой посуды. Самый подлый, самый нестерпимый мат - женский...» [УлицКАЯ 2006: 154]. Мур так и не названа матерью в тексте, даже ее дочь думает о ней, только как о «Мур». Пример нецензурной речи героини - «с херакой у него обстояло из рук вон плохо» [УЛИЦКАЯ 2006: 93] - содержит производное слово от *хер, которое соединяется с широко известным фразеологизмом «из рук вон плохо». Словесное ругательство Мур создает истинно театральную сцену. Услышав брань, водитель такси, «парень с дипломом театрального института» «прислонился к стене, наслаждаясь неожиданным театром» [УлицКАЯ 2006: 156].

Дело в том, что Мур не разрешает своей семье уехать к Мареку на греческий остров, который мог бы стать для них райским местом для спасения и устранения их «безотцовщины», вызванную ее же действиями. По этой причине и становится эмблематичным событием попытка у других членов семьи противостоять ее прихоти. Мужелюбивая, но смертоносная Мур же не только огораживает женщин своей семьи от внешнего мира, мужчин, но она также не позволяет своему незаконнобрачному правнуку, единственному мальчику в семье, увидеть мужской образец в виде его деда. Она сворачивает в комок письмо-приглашение Марека и показывает Грише фигу. Ласковое мурлыкание и стеклянный крик противопоставляются точно так же, как сравнение Гриши при приезде такси: «дрожащий от нетерпения, как щенок перед утренней прогулкой» [УлИЦКАЯ 2006: 156], и акт действия героини при получении письма Марека с приглашением: «фыркнула Мур» [УлицКАЯ 2006: 147]. Здесь разворачивается настоящий конфликт рассказа - сцепление собаки и кошки, мужчины и женщины. «Боевые» действия, жест героини отмечен красным цветом (ср. ее крашеные ногти) и вербальной манифестацией «нападения». Мур показала правнуку «фигу с сильно торчащим вперед ярко-красным ногтем большого пальца. Второй рукой она ловко выхватила приглашение из рук опешившего мальчишки, не ожидавшего такого дерзкого нападения. Опершись локтями о перильца, она скомкала конверт и бросила плотный, как хороший снежок, бумажный ком прямо к входной двери...» [УлицКАЯ 2006: 148].

Уподобление бумажного комка снежку коннотирует игру, превращенную в настоящий бой на уровне вербального конфликта, ибо мальчик в ответ употребляет такой же нецензурный мат, как его прабабушка: «-Гадина поганая! Сука гребаная!» [УлицКАя 2006: 148]. Он теряет самообладание словно Германн у Пушкина, однако его слова не приводят к внезапной кончине старухи. Мур же со своей стороны только со спокойным достоинством изображает обиженную жертву. Ходильная машина Мур скрипит колесиками подобно ее матерным словам, «стеклянному крику». Но и тихая модальность ее слов ужасающая, ибо обозначает оскорбление в сторону ребенка и его матери Кати: «Приспустив печальные веки, Мур с тихой укоризной обратилась к внучке:-Забери 
своего выблядка, деточка. Деточка, детей надо воспитывать, - поскрипывая колесиками, поехала на кухню» [УлицКАЯ 2006: 148].

Бунт подавленной дочери Мур, Анны Федоровны возникает только в ее воображении. Презентация поступка бунта в тексте строится с одной стороны, на звуковых повторах (*раз/с, сла), а с другой стороны, на действенных поэтических эпитетах: «И увидела вдруг как уже совершенное: она, Анна, размахивается расслабленной рукой и наотмашь лепит по старой нарумяненной щеке сладкую пощечину...» [УлицКАЯ 2006: 154]. Фраза «нарумяненная щека» устанавливает семантическую связь с красным цветом и искусственностью Мур, а «сладкая пощечина», размещенная «расслабленной рукой» Анны Федоровны, содержит ее же точку зрения - это ей становится сладко поднять руку на свою мать, которая отравляет всем, в том числе и ей, жизнь. В начале рассказа одетая в черное платье Мур не позволяет своей дочери выпить черный кофе, требуя себе черный шоколад с молоком, а затем отказывается от своего же желания. В конце рассказа требование «черной» героиней «белого» молока (ср. кошка) в кофе посредственно приводит к смерти ее дочери, образ которой в тексте носит светлые краски. Таким образом в рассказе тематизируется цветовая метафорика.

Синий свет, как раньше серый, начинает определять образ героини. Здесь он переносится на небо, которое сопоставляется с глазом [МОЛНАР - НИКОлинА 2019: 98]. Напомним, что Анна Федоровна - офтальмолог (глазной врач). Метафорический ряд посредством дигрессий переходит в высказывание, дополняясь и зеленым цветом сквера, расположенного возле церкви Скорбящей Богоматери: «и чистейшая зелень прибранного скверика возле уютной округлой церкви Всех Скорбящих» [УлицКАЯ 2006: 153]. Наименование сакрального здания позволяет установить аналогию между образом героини Улицкой и Божьей Матерью. Анна Федоровна именно в этом месте и «упала вперед» [УЛИЦКАЯ 2006: 154].

Двигательная коляска (механизм) в тексте рассказа переименуется в «клеточку» и «капитанский мостик» корабля, управляющего жизнью семьи, когда Катя после смерти своей матери, словно мстя за нее, реализует ее фантазию и ударяет Мур в лицо. Таким образом, развертывается изначальная метафоризация текста «Пиковой Дамы» Улицкой (ср. колесики). «Катя подошла к Мур и, размахнувшись расслабленной рукой, наотмашь влепила по старой, еще не накрашенной щеке сладкую пощечину. Мур мотнулась в своей клеточке, потом замерла, вцепилась в поручни капитанского мостика, с которого она последние десять лет, после перелома шейки бедра, руководила всеобщей жизнью, и сказала внятно и тихо: - Что? Что? Все равно будет так, как я хочу...Катя прошла мимо нее, на кухне вспорола пакет и плеснула молоко в остывший кофе» [УЛИЦКАЯ 2006: 157]. Разница между совершаемым жестом пересечения границы и описанием воображаемого поступка Анны Федоровны это то, что Мур здесь еще не накрасилась и не кричит, а отвечает тихо, что все будет по ее хотению. Катя действует вместо своей матери и тогда, когда в заключении рассказа она наливает в кофе молока, потребованного Мур. Кофе уже 
остыло, стало таким холодным, как молоко и окружающий, заснеженный мир. Образы молока и снежного мира связывает и белый цвет. Результата от удара, как бунта, однако нет, ибо, предположительно, все продолжится в прежней колее.

\section{Выводы}

Метафоризация в рассказе Улицкой развертывает кризисную ситуацию. Созданные тропы играют важную роль в порождении нового значения бунта и пересечения границы. Из этого следует также, что поэтические элементы становятся необходимыми составляющими не только для генерирования нового литературного текста, но также для переосмыслении события-пуанта.

\section{Литература}

ЗАВьяЛовА 2016: Завьялова, Е.Е. «Пиковая дама» Л.Е. Улицкой в свете традиций рождественского рассказа // Трансформация жанра в историко-литературном процессе.(под ред. проф. Г.Г. Исаева). Астрахань, ИД «Астраханский университет», 70-75.

ИшкинА 2003: Ишкина, Е.Л. Поэтика рассказов Л. Улицкой // Актуальные проблемы современной филологии. Литературоведение. Киров, 102-104.

Колядич 2004: Колядич, Т.М. Своеобразие организации циклов рассказов Л. Улицкой // Литературный процесс в зеркале рубежного сознания. - Магнитогорск, 332-334.

МолНАР - НиколинА 2019: Молнар, А.-Николина, Н. Типы и функции компаративных тропов в современном прозаическом тексте (на материале рассказа Л. Улицкой) // Slavica 48: 96-100.

ПоБИВАЙЛО 2007: Побивайло, О.В. Опыт психоаналитического прочтения рассказа Л. Улицкой «Пиковая дама» // Молодежь - Барнаулу - 2006: сборник трудов городской научно-практической конференции молодых ученых. Барнаул, Издательство БГПУ, 98-99.

САВКИНА 2016: Савкина, И.Л. Пиковая дама: Женственность и старость в современной российской женской литературе. // Уральский филологический вестник. Серия: Русская литература XX-XXI веков: направления и течения. № 1. 275-288.

САФоновА 2009: Сафонова, Е.Г. «Пиковая Дама» Людмилы Улицкой: категории пространства - времени в произведении: [11 кл.] // Литература, 36-38.

УлицКАя 2006: Улицкая, Л.Е. Пиковая дама // Улицкая Л.Е. Первые и последние: Рассказы. Москва, Эксмо, 87-157.

ШтыровА 2013: Штырова, А.Н. Образ «la femme fatale» в повести «Вешние воды» И.С. Тургенева и рассказе «Пиковая Дама» Л.Е. Улицкой // Филология и литературоведение. №4 [Электронный ресурс].

URL: http://philology.snauka.ru/2013/04/469 (дата обращения: 08.03.2020).

ЩукинА 2011: Щукина, Д.А. Символика интертекста в русской литературе XXI века // Мир русского слова. № 3. Санкт-Петербург, 80-83.

Ангелика МОЛНАР

Дебреценский университет

Дебрецен, Венгрия

molnar.angelika@arts.unideb.hu 